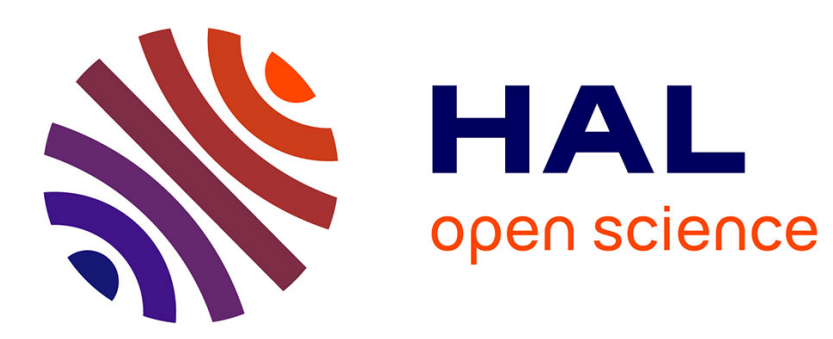

\title{
From Routine To Better Network Services
}

Eduardo Mucelli Rezende Oliveira, Aline Carneiro Viana

\section{To cite this version:}

Eduardo Mucelli Rezende Oliveira, Aline Carneiro Viana. From Routine To Better Network Services. WMNC - Wireless and Mobile Networking Conference - 2014, Apr 2014, Algarve, Portugal. hal00931801v2

\section{HAL Id: hal-00931801 \\ https://hal.inria.fr/hal-00931801v2}

Submitted on 17 Jan 2014

HAL is a multi-disciplinary open access archive for the deposit and dissemination of scientific research documents, whether they are published or not. The documents may come from teaching and research institutions in France or abroad, or from public or private research centers.
L'archive ouverte pluridisciplinaire HAL, est destinée au dépôt et à la diffusion de documents scientifiques de niveau recherche, publiés ou non, émanant des établissements d'enseignement et de recherche français ou étrangers, des laboratoires publics ou privés. 


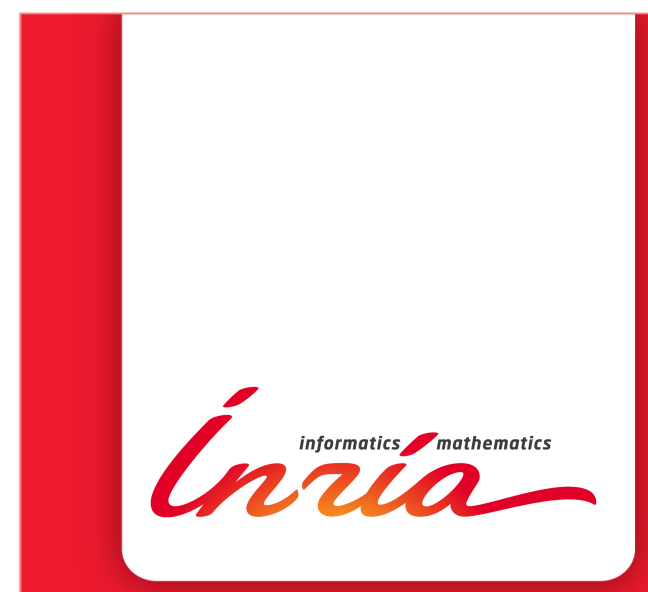

\section{Des Routines}

Quotidiennes aux

Meilleurs Services

Réseaux

Eduardo Mucelli Rezende Oliveira, Aline Carneiro Viana

\section{RESEARCH}

\section{REPORT}

$\mathrm{N}^{\circ} 8451$

January 2014

Project-Teams 



\title{
inzián
}

\section{Des Routines Quotidiennes aux Meilleurs Services Réseaux}

\author{
Eduardo Mucelli Rezende Oliveira ${ }^{*}$, Aline Carneiro Viana * \\ Équipes-Projets
}

Rapport de recherche $\mathrm{n}^{\circ} 8451$ - version 2 - version initiale January

2014 - version révisée January 2014 - 12 pages

\begin{abstract}
Résumé : Dans ce travail, nous évaluons le comportement routinière des personnes et soulignons les moyens de l'explorer afin de fournir de meilleurs services réseaux. Nous avons étudié deux ensembles de données réelles décrivant plus de 6 ans de trajectoires des personnes dans leur vie quotidienne. Les résultats montrent que les personnes tendent en effet à prendre des chemins les plus courts quelle que soit le mode de transport. En outre, il s'agit d'un comportement collectif, pas un comportement spécifique d'un certain groupe de personnes. Enfin, les personnes manifestent deux autres caractéristiques sur leurs habitudes de mobilité: trajectoires très confinées et répétitives. Nous avons alors présenté plusieurs scénarios dans lesquels des solutions de réseaux peuvent être fournies en profitant de ces comportements.
\end{abstract}

Mots-clés : routine, réseaux, services réseaux

* This work was supported by the EU FP7 ERANET program under grant CHIST-ERA-2012 MACACO.

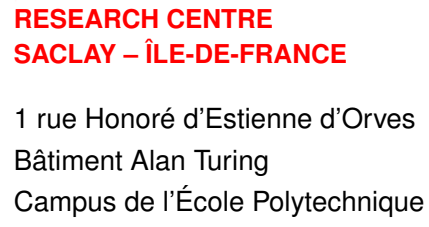




\title{
From Routine To Better Network Services
}

\begin{abstract}
In this work, we assess the routinary behavior of people and point out means to explore it in order to provide better network services. We have studied two real datasets representing together more than 6 years of trajectories from people's daily lives. The results show that people indeed tend to take shortest paths regardless the transportation mode. Furthermore, it is a collective behavior, not a specific behavior of a certain group of people. Finally, people demonstrate more two characteristics on their mobility patterns: highly confined and repetitive trajectories. We have then presented several scenarios in which network solutions might be provided taking advantage of those behaviors and some ways to approach them.
\end{abstract}

Key-words: routine, networks, network services 


\section{Introduction}

People are routinary semi-rational entities, they have regular circles of actions guided by their decisions but unexpected situations may interfere on their directions [1. A person may change their itinerary due to a traffic jam, problems on the public transportation, etc. When choosing an itinerary, people tend to use the shortest-path to reach their destination, also known as "desire line". The desire line is the shortest path between origin and destination, and expresses the way a person would like to go, if such a way were available [2. Furthermore, the people's itinerary is characterized by its confinement, i.e., despite of choosing the shortest-paths, people will roam repetitively close by their main physical address $[3$.

Social ties among users have been widely exploited in opportunistic mobile networks to favor network services [4, 5. Nevertheless, still few works have been investigating user mobility in terms of their trajectories and daily space-time routines. On the other hand, we are going to assess the trajectories that people produce on their daily activities in two cities counting more than 2200 days span in order to understand how short and routinary the routes are.

To accomplish our objective, we study real-life mobility traces (cf. Section 3) of people in two metropolitan areas, namely Beijing and Tokyo, and measure two key characteristics of their routines, Confinement (cf. Section 3.3) and Shortest-paths (cf. Section 3.4). Results reveal that $83 \%$ and $95 \%$ of the trajectories for Beijing and Tokyo, respectively have, at most, $10 \mathrm{~km}$ maximum displacement, i.e., people have their mobility confined. Furthermore, results show that, on average, $70 \%$ of the trajectories are, at most, half longer than the shortest path regardless of the transportation mode. Section 4 discusses some scenarios in which network solutions might take advantage of daily trajectories based on the measurements herein presented in order to provide people with better network services. Finally, Section 5 concludes this work.

\section{Related Work}

Human mobility has been widely studied, mainly focusing on the relation between people. Remarkably, [6] studied the implication of mobility on how separated people are and concluded that, in United States, people seemed to be separated by three acquaintance links.

More recently, the shortness of displacement was assessed by analysing the circulation of bank notes in the United States 3. From a total of 20,540 short-time trajectories originating across the United States, results for three major cities, namely Seattle, New York, Jacksonville, shown that the probability of a trajectory measuring less than $10 \mathrm{~km}$ were $57.7 \%, 57.7 \%$ and $71.4 \%$, respectively. On contrary to bank notes, our data is represented by GPS tracks which seems to be one of the most accurate ways to track mobility of people.

Regarding routinary visit of places, [7] proposed a solution to identify points of interest based on people's mobility characteristics. Our work differs since we are not interested on the points of interest but on the routinary characteristics present on people's trajectories.

\section{Evaluation}

To assess the routinary characteristics on people's daily lives we have used two datasets describing mobility on two big metropolitan areas, Beijing and Tokyo. The following subsections describe their characteristics. 


\subsection{Datasets}

In this work, we are using two datasets, GeoLife on its latest version [8] and a crawled dataset from OpenStreetMap [9]. GeoLife is considered to be unique in the literature. This is due to the fact that it provides a rich view of people mobility using 11 different transportation modes in an urban area for a long period of time. It provides geolocalized and timestamped points from 182 people during spread on 1600 days, from April 2007 to October 2011, mostly in Beijing. OpenStreetMap is collaborative open geodata online map that started in 2008 and currently has more than 1.3 million registered users. On OpenStreetMap, an user may upload his GPS tracks using GPX format that describes his geolocalized coordinates during the time. From it we have crawled user GPS tracking data from several cities using their API ${ }^{1}$ From this set we have chosen to use a subset containing information from users in Tokyo, one of the biggest cities in terms of available data. Tokyo dataset contains 88 people during 606 days from August 2007 to September 2013.

For each person, both datasets provide a set of geolocalized points, i.e., a GPS trajectory ascendingly sorted by timestamp. Trajectory represents how people moves around and is described as a set of points representing GPS coordinates periodically collected. In GeoLife dataset, people may move around building their trajectories using at most ten different transportation modes such as taxi, bike, run, bus, walk, train, subway, car, boat, and motorcycle. It is important to enhance that transportation mode information is not available for all trajectories on GeoLife and it is not available at all in Tokyo dataset. When it comes to assess mobility of people, the transportation mode is an important information. Indeed, transportation mode could change completely the network demands coming from people's devices : e.g., a person riding a bike has a different context than someone inside a bus, therefore, the former will be less susceptible to use the phone than the latter. In order to label the unlabeled trajectories, we have created a simple model that sets a transportation mode depending on the average speed in which the person is traveling. Section 3.2 describes in details how trajectory labeling was performed.

Moreover, to better understand specific behaviors inherent from different periods of the day, every day is divided into four periods of 6 hours, from 00 :00 to $05: 59$, from 06 :00 to $11: 59$, from $12: 00$ to $17: 59$, and from $18: 00$ to $23: 59$.

\subsection{Labeling}

Not every trajectory from the datasets herein considered are labeled with transportation modes. That is due to the fact that labeling was not mandatory for people participating on the GeoLife experiment nor it is an expected information on OpenStreetMap GPS data. A trajectory may have at least one transportation mode label. Each subset of points with a unique transportation mode contained in a trajectory is called leg. For example, a trajectory composed by two legs, "car" and "walk" representing a situation in which a person went by car to his work, parked the car and went walking until his office.

Our model labels trajectories by their average speed, which is calculated considering both the length and the duration of the traveled leg. The result is matched against known speed ranges on the city. Table 1 describes average speed ranges by transportation mode in Beijing. We have used the same ranges to assign labels to the legs in Tokyo. Lets consider we have an unlabeled leg $l$ traveled with average speed of $5 \mathrm{~m} / \mathrm{s}$. Consulting the Table 1 , it is possible to see that $l$ falls on a range in which three transportation modes present overlapping average speed ranges, taxi, motorcycle, and car. Therefore, each one has equal chance of being chosen by a randomly

1. http://wiki.openstreetmap.org/wiki/API_v0.6 
TABLE 1 - Average speed $(\mathrm{m} / \mathrm{s})$ ranges by transportation mode

\begin{tabular}{cc}
\hline Transportation mode & Average speed range \\
\hline Walk & $\leq 1.5$ \\
Bus & $>1.5$ and $\leq 4[10]$ \\
Bike or Run & $>4$ and $\leq 4.4[11]$ \\
Taxi, Motorcycle, or Car & $>4.4$ and $\leq 11.5[12]$ \\
Subway & $>11.5$ and $\leq 28[13]$ \\
Train & $>28$ and $\leq 250$ \\
Airplane & $>250$ \\
\hline
\end{tabular}

uniformly distributed number. In this example, $l$ will be labeled either as 'taxi', 'motorcycle', or 'car' with $33 \%$ of chance.

The transportation mode of a leg will be used to calculate its known shortest path. Therefore, in cases where labels are dividing a speed range, i.e., (1) 'bike' and 'run' and (2) 'taxi', 'motorcycle' and 'car', there is not negative impact on assigning a specific label instead of another in the same range. That is because the shortest path for labels in (1) is calculated differently for labels in (2) (cf. Section 3.4).

\subsection{Confinement}

To understand how the routine occurs on our scenario, we have measured how confined and repetitive the trajectories are.

In order to measure how confined are the trajectories, for each trajectory, we have calculated the maximum displacement, i.e., the distance between its initial and farthest point (not necessarily the last point). Fig. 1 presents the CCDF of the maximum displacement for all trajectories grouped by period on both datasets. It shows that $83 \%$ and $95 \%$ of the trajectories for Beijing and Tokyo respectively, have at most, $10 \mathrm{~km}$ maximum displacement and the period of the day does not affect this behavior. This result shows that generally people do not move far away from their starting point, and presents high confinement. Results shown in [3] reveal that the percentage of trajectories with displacement less than $10 \mathrm{~km}$ ranged from $52 \%$ to $71 \%$. GPS tracking seems to be one of the most accurate ways to track mobility of people. Therefore, we believe that the higher confinement presented in our results is a more precise measurement of human displacement on an urban scenario.

People with confined mobility tend to repetitively visit the same areas. To understand how people explore the regions, central Beijing and Tokyo were divided into square-shapped cells of 50 $m^{2}$ summing up 800 and 916 thousand cells, respectivelly. Then, we have calculated the number of unique cells $(N U C)$ and total cells $(N T C)$ that each trajectory visited. To quantitatively express the percentage of confinement of a trajectory, a metric called Repetitiveness was conceived and is represented as the following: $\frac{N T C-N U C}{N T C} * 100$

Repetitiveness of a trajectory represents how repetitive is the route described by this trajectory. Regardless of the period of the day, trajectories present a considerable amount of repetitivity on both datasets. In Beijing, $90 \%, 89 \%, 90 \%$ and $92 \%$ of the performed trajectories present at most $50 \%$ of repetitiveness (i.e., half of the cells are repetitively visited) for periods from $00: 00$ to $05: 59$, from $06: 00$ to $11: 59$, from $12: 00$ to $17: 59$, and from $18: 00$ to $23: 59$, respectively. Tokyo presents similar results, $98 \% 93 \% 94 \% 95 \%$ for periods from 00 :00 to 05 :59, from $06: 00$ to $11: 59$, from $12: 00$ to $17: 59$, and from $18: 00$ to $23: 59$, respectively. An interesting aspect of this results is to understand if the repetitiveness is related to the amount of trajectories per- 
formed by people and possibly to the amount of visited cells : "Does repetitiveness occurs less where less trajectories are performed?". Revisiting areas is a consistent personal behavior that does not rely on the amount of trajectories that were performed on a certain period. In Beijing, both periods from 06 :00 to $11: 59$ and from 00 :00 to 05 :59 have high and similar repetitiveness rates but the former has 6.4 times more trajectories than the latter. Similarly in Tokyo, period from 12 :00 to $17: 59$ has 21 times more trajectories than the period from 00 :00 to 05 :59 but they present similar results.

On the other hand, repetitiveness also may be used to represent how repetitively a cell receives visits. The repetitiveness of a cell is based on the number of unique users (NUU) and total users $(N T U)$ that visited it as following : $\frac{N T U-N U U}{N T U} * 100$. Fig. 2 (better seen in colors) shows a heatmap by period of the day colored by repetitiveness values of each cell. This result depicts that repetitiveness is power-law distributed throughout the cells, i.e., while most of the cells receive few visits, few cells receive most of the visits. Indeed, $78 \%, 77 \%, 77 \%$ and $87 \%$ of the cells in Beijing have, at most, $5 \%$ of repetitiveness (i.e., $5 \%$ of users revisited it) for periods from $00: 00$ to $05: 59$, from $06: 00$ to $11: 59$, from $12: 00$ to $17: 59$, and from 18 :00 to $23: 59$, respectively. Besides, $0.4 \%, 0.2 \%, 0.2 \%$ and $0.2 \%$ of the cells in Beijing have more than $90 \%$ of repetitiveness for periods from $00: 00$ to $05: 59$, from 06 :00 to $11: 59$, from 12 :00 to $17: 59$, and from 18 :00 to $23: 59$ respectively. People repetitively visit the same cells (high repetitiveness of trajectories shown previously), resulting in some few areas being highly popular, while most of the areas are unpopular. Regardless of the period of the day, a north central area consistently shows cells with hight repetitiveness, which is due to the fact that Microsoft Research Asia headquarter is located there. GeoLife experiment was conduced mostly with Microsoft members that were constantly walking nearby the working place.

Tokyo presents similar results, $76 \%, 75 \%, 72 \%$, and $83 \%$ of its cells have, at most, $5 \%$ of repetitiveness for periods from $00: 00$ to $05: 59$, from $06: 00$ to $11: 59$, from $12: 00$ to $17: 59$, and from 18 :00 to $23: 59$, respectively. On the other hand, $0.1 \%, 0.8 \%, 0.2 \%$, and $0.07 \%$ of the cells have more than $90 \%$ of repetitiveness for periods from $00: 00$ to $05: 59$, from 06 :00 to $11: 59$, from $12: 00$ to $17: 59$, and from $18: 00$ to $23: 59$ respectively. Two remarkable areas are presented on Tokyo's heatmap : (1) Kodaira Train Station on the northwest presents high repetitive from 06 :00 to $11: 59$ and (2) Motosumiyoshi Station on the south highly active from 06 :00 to $11: 59$ and from $12: 00$ to $17: 59$. Both present the characteristic of big train stations, high repetitive values due to people going to and from their daily activities commuting in those station.

\subsection{Shortest-paths}

The concept of "desire lines" states that people tend to choose the shortest-paths to arrive on their destinations. In order to verify that, we have compared the length of each traveled leg against the length of the corresponding shortest path considering the same initial and final points of the original leg. Dividing the length of the original leg by the length of the shortest path allows us measuring how longer the path made by a person is from the shortest path. We have used Google Directions API ${ }^{2}$ to compute the shortest path. The API receives the coordinates of both initial and final points and a travel mode, i.e., transportation mode. Then, it returns the shortest path considering the restrictions imposed by the existing routes and obstacles in the city for a specific transportation mode. Note that, we only have considered transportation modes where people have decision control of their paths. This excludes for example, buses, boats or trains.

Legs traveled by walking, running, and biking had their lengths divided by their respective shortest paths computed while using the API in walking mode. Google Directions API indeed has a bicycling travel mode, but at the moment, it does not contain routes neither in Beijing nor

2. https://developers.google.com/maps/documentation/directions 


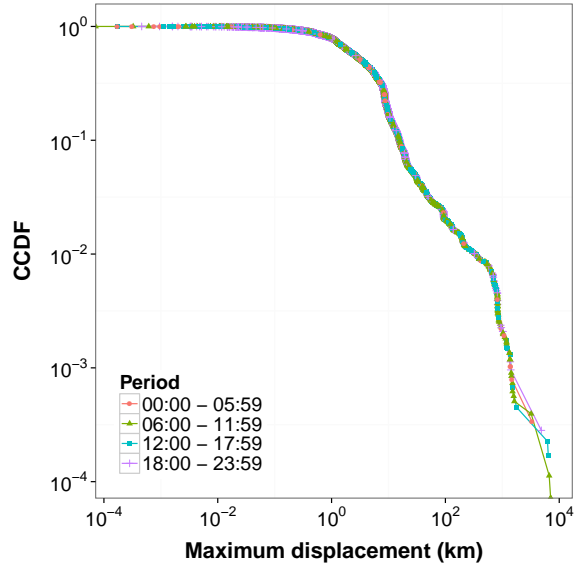

(a) Beijing

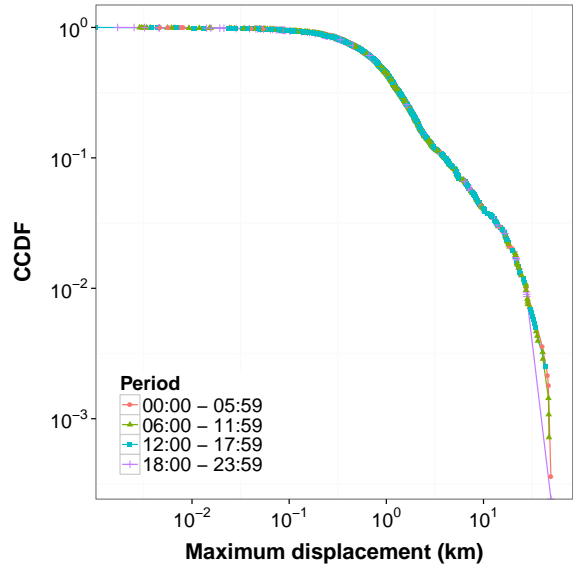

(b) Tokyo

FiguRE 1 - CCDF of the maximum displacement.

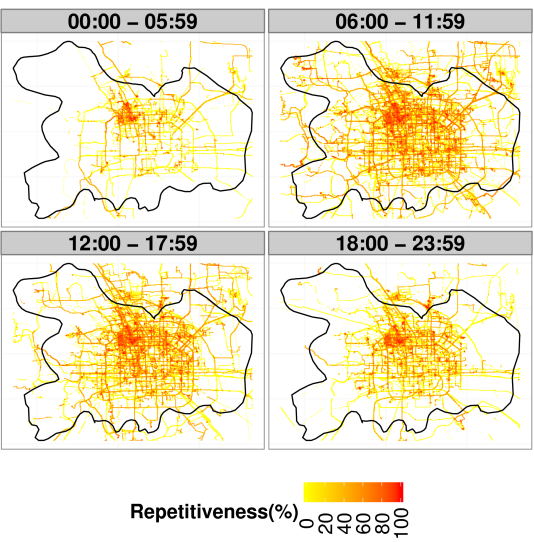

(a) Beijing

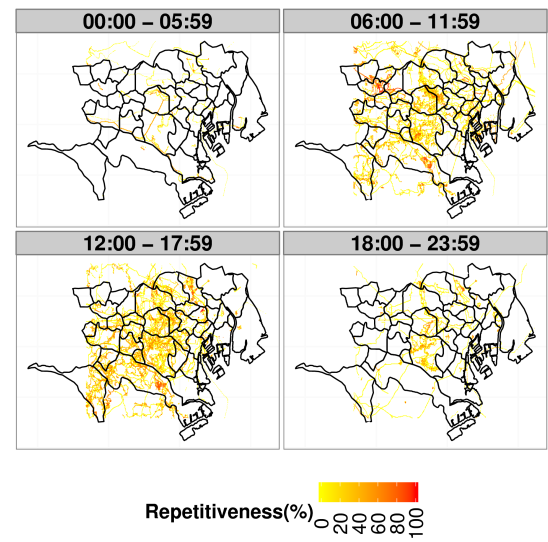

(b) Tokyo

Figure 2 - Heatmap of the Repetitiveness by grid cell (better seen in colors).

in Tokyo. Legs traveled by taxi, car, and motorcycle had their lengths divided by results of the API in the driving mode. Fig. 3 shows the CCDF of the ratio between the original legs length and the Google shortest path, by transportation mode and period of the day.

For Beijing, it shows that the periods from $00: 00$ to $05: 59$, from $06: 00$ to $11: 59$, from $12: 00$ to $17: 59$, and from 18 :00 to $23: 59$ present, respectively, $60 \%, 72 \%, 65 \%$ and $79 \%$ of the legs measuring, at most, half longer than the shortest path. That results show that on late night people tend to walk around not directly going to their destination. Indeed, on late night people tend to go for bars, night clubs and are more susceptible to create routes that are way longer than the shortest ones. On the other hand, periods representing early morning and early night show high percentage of legs closest to the shortest one and describing how people go directly to their destinations, e.g., work, home, etc. The period containing the early afternoon hours present an intermediate percentage of legs close to the shortest path. Indeed, this period 
mixes people walking around careless about shortest paths (e.g, someone shopping, or looking for restaurants), and people more concerned about their being on time (e.g, people coming back from the lunchtime towards the work). Moreover, it is possible to see that the length ratio does not change in function of the transportation mode. It shows that regardless of the transportation mode, people tend to be oriented by the shortest paths.

On the other hand, Tokyo presents $56 \%, 49 \%, 46 \%$ and $61 \%$ ratio for periods from $00: 00$ to $05: 59$, from $06: 00$ to $11: 59$, from $12: 00$ to $17: 59$, and from $18: 00$ to $23: 59$, respectively. Indeed, those values are smaller when compared with GeoLife results. That is due to the fact that $48 \%$ of days contained on OpenStreetMap dataset are on weekends, i.e., Saturday and Sunday, contrary to GeoLife that counts $27 \%$ of its days on weekends. Therefore, in this case, OpenStreetMap presents trajectories composed of mixed behaviors inherent from the differences between working days and weekend days, e.g., people performing short routes going straight to work and people making longer routes roaming around while shopping.

Finally, it is important to understand whether the legs with low length ratio are performed by a small group of people or throughout a large group, i.e., "Is the usage of shortest paths an isolated tendency or a collective behavior ?". To do so, we calculate, for each period of the day, the cumulative percentage of users. Length ratio values were taken in steps of 0.5. For each step, we calculate the percentage of users who performed, at least, $50 \%$ of legs shorter than the step. We calculate the percentage relative to the number of users on each period. Fig. 4 shows the cumulative percentage of users in function of the length ratio grouped by period of the day. For Beijing, it shows that $67 \%, 75 \%, 66 \%$, and $77 \%$ percent of the users perform mostly legs that are, at most, half longer than the shortest ones respectively for periods from 00 :00 to $05: 59$, from $06: 00$ to $11: 59$, from $12: 00$ to $17: 59$, and from $18: 00$ to $23: 59$. Finally, for the same metric Tokyo presents $43 \%, 60 \%, 35 \%$ and $72 \%$ for periods from $00: 00$ to $05: 59$, from $06: 00$ to $11: 59$, from $12: 00$ to $17: 59$, and from $18: 00$ to $23: 59$. Therefore, the usage of shortest paths is indeed a collective behavior.

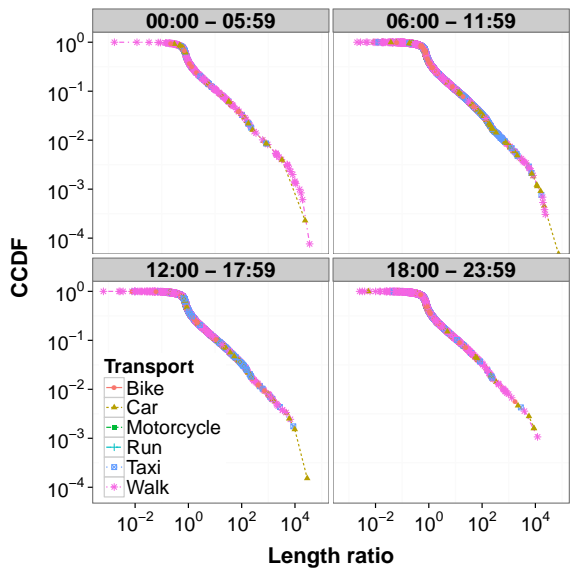

(a) Beijing

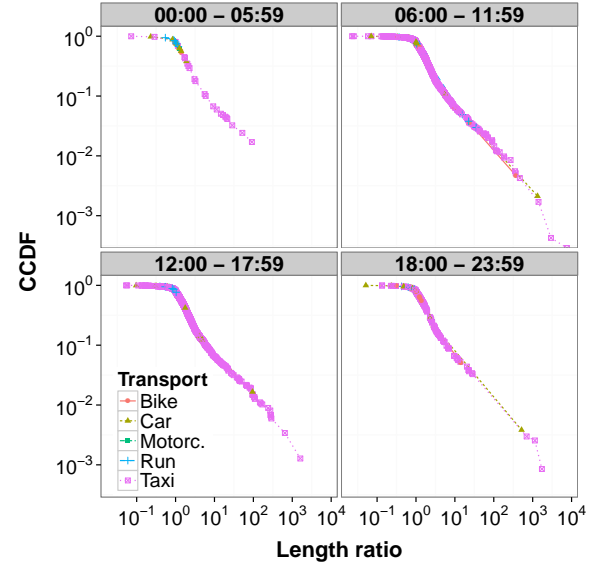

(b) Tokyo

Figure 3 - CCDF of the length ratio by period. 


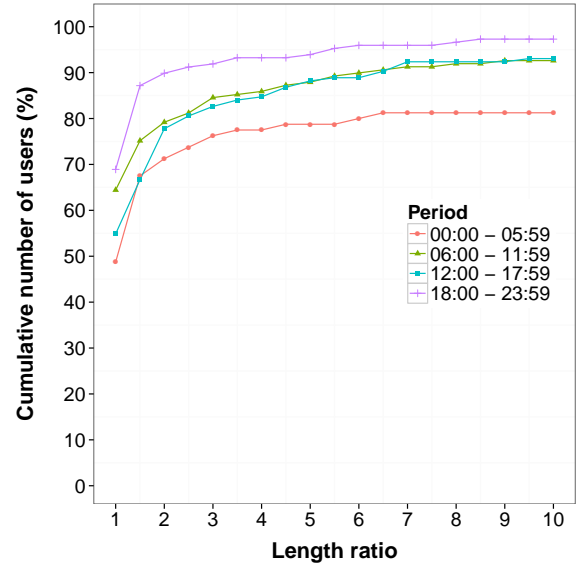

(a) Beijing

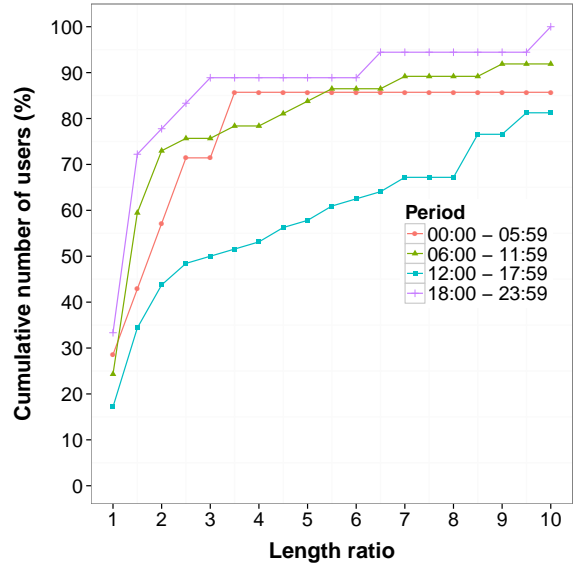

(b) Tokyo

FIgURE 4 - Percent of users as a function of the length ratio by period.

\section{Discussion}

Understanding human mobility behavior is a key aspect to develop better network services and solutions on several areas. This section discusses some applications that may benefit from mobility aspects previously presented. Furthermore, GeoLife is a rich dataset suitable for studying routine-based services but has not been much explored in the literature. On the other hand, OpenStreetMap is still collaboratively building its GPS tracking dataset and it is not as rich as GeoLife in this aspect for any specific city.

Forwarding Protocols An important problem on Pocket Switched Networks area is how to couple human mobility patterns with message forwarding algorithms [14. Routinary behavior has been widely studied when it comes down to encounters among nodes. On the other hand, trajectories behavior could be studied to improve protocols based on store-and-forward late delivery. How far a person routinely goes or how frequently one visits the same places in a city could be important characteristics to define the potential of a peer to be chosen to keep a message to be routed. For instance, the few percentage of people going routinely further than the $10 \mathrm{~km}$ mark could be important routers on a Pocket Switched Network [15].

Social Hotspot Deployment Unplanned deployment of hotspots may lead to both underutilized and over-utilized network areas. The expansion of metropolitan areas increased the possibility of moving around. This fact together with the increase of smartphone use results in highly dynamic links, which may significantly affect the performance of the network. Moreover, people may use different transportation modes, which significantly impacts their trajectories. Mobilityoriented deployment may be an important point while projecting a network deployment. For instance, areas in which people frequently visit during their routinary behavior may be used as key areas to deploy a complementary network, e.g., WiFi hotspots providing data-offloading points for a $3 \mathrm{G}$ network [16.

Routine-based Data Prefetching Prefetching has been shown to effectively reduce user perceived latency. An interesting approach might be to merge trajectory information with demanded 
content in order to provide a smart data prefetching approach. Based on the routine of person, a prefetching service could, for example, store static content of web pages visited often. This content could be downloaded using access points present in the places routinely visited by the person. For instance, an application for mobile phones could download content in advance at home using $\mathrm{WiFi}$ and this would be later presented along with content downloaded using $3 \mathrm{G}$ in real time. This approach could alleviate the usage of $3 \mathrm{G}$ by shifting to inexpensive networks (such as WiFi) the load of static content such as images.

Public Transportation Planning Monitoring, distributing, and processing traffic information may enable better strategic planning and encourage better use of public transportation. Several applications may take advantage of the driver's routinary behavior in order to improve aspects of the Vehicular Networks. For instance, traffic information, e.g., accidents, construction sites, traffic jams may be exchanged between vehicles. On a routinary scenario, all those information may be used to forecast the situation for the next days and alert the driver, for example, about possible alternative roads. Besides, a service may identify points of interest based on driver's mobility patterns. Identify parking lots and its availability in number of spots, or suggest the best charging station for electrical vehicles based on the driver's routine and battery conditions. Furthermore, a service to advertise products on roadside signs may merge different sources of information in order to display targeted marketing. By crossing information from the driver's routinary trajectories, traffic condition and the driver's interests, a service could present ads that match driver's interest on a certain area of the city likely having the driver on its vicinity. On a collaborative scenario, a carpooling service could suggest people to get or to offer a ride based on regular driver's destinations and passengers interested on ride-sharing.

\section{Conclusion}

In this work, we have assessed the routinary behavior of people and pointed out means to explore it in order to provide better network services. We have studied a two real datasets representing together more than 2200 days from people's daily lives in Beijing and Tokyo. The results show that people indeed tend to take shortest paths regardless the transportation mode and that it is a collective behavior, not a specific behavior of a certain group of people. In addition, people demonstrate more two characteristics on their mobility patterns : highly confined and repetitive trajectories. For instance, $83 \%$ and $95 \%$ of the trajectories for Beijing and Tokyo respectively, have at most, $10 \mathrm{~km}$ maximum displacement regardless the period of the day. Besides, on average, $70 \%$ of the trajectories are, at most, half longer than the shortest path regardless of the transportation mode. We have also presented (1) several network scenarios which might take advantage of those behaviors and (2) some possible ways to provide better network services on such scenarios. As future work, we envision to study routine-based deployment solutions with the purpose of providing a data-offloading architecture.

\section{Table des matières}

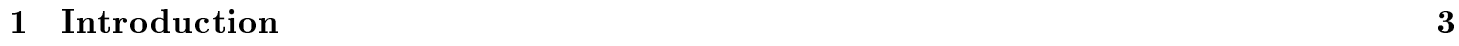

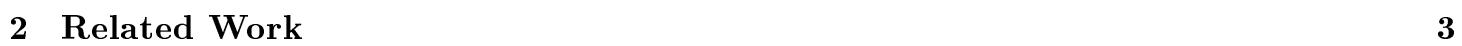

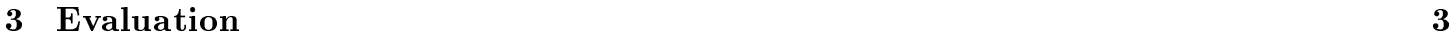

3.1 Datasets . . . . . . . . . . . . . . . . . . . . . . 4 
3.2 Labeling . . . . . . . . . . . . . . . . . . . . . . . . . 4

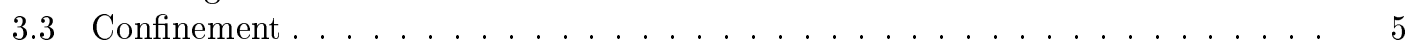

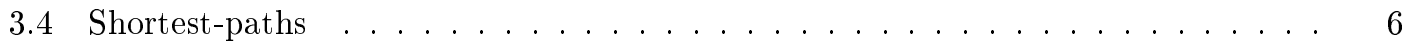

4 Discussion 9

$\begin{array}{ll}5 \text { Conclusion } & 10\end{array}$

\section{Références}

[1] D. S. Hamermesh, "Routine," National Bureau of Economic Research, Working Paper 9440, January 2003. [Online]. Available : http://www.nber.org/papers/w9440

[2] J. A. Throgmorton and B. Eckstein. (2000, Nov.) Desire lines : The chicago area transportation study and the paradox of self in post-war america. [Online]. Available : http://www.nottingham.ac.uk/3cities/throgeck.htm

[3] D. Brockmann, L. Hufnagel, and T. Geisel, "The scaling laws of human travel," Nature, vol. 439, no. 7075 , pp. 462-465, Jan. 2006. [Online]. Available : http: //www.ncbi.nlm.nih.gov/pubmed/16437114

[4] A. Chaintreau, P. Hui, J. Crowcroft, C. Diot, R. Gass, and J. Scott, "Impact of human mobility on opportunistic forwarding algorithms," IEEE Transactions on Mobile Computing, vol. 6, no. 6, pp. 606-620, Jun. 2007. [Online]. Available : http://dx.doi.org/10.1109/TMC.2007.1060

[5] A.-K. Pietilänen and C. Diot, "Dissemination in opportunistic social networks : the role of temporal communities," in Proceedings of the thirteenth ACM international symposium on Mobile Ad Hoc Networking and Computing, ser. MobiHoc '12. New York, NY, USA : ACM, 2012, pp. 165-174. [Online]. Available : http://doi.acm.org/10.1145/2248371.2248396

[6] S. Milgram, "The small world problem," Psychology Today, vol. 1, no. 1, pp. 61-67, 1967.

[7] M. Papandrea, M. Zignani, S. Gaito, S. Giordano, and G. Rossi, "How many places do you visit a day?" in Pervasive Computing and Communications Workshops (PERCOM Workshops), 2013 IEEE International Conference on, 2013, pp. 218-223.

[8] Y. Zheng, X. Xie, and W.-Y. Ma, "Geolife : A collaborative social networking service among user, location and trajectory," IEEE Data Eng. Bull., vol. 33, no. 2, pp. 32-39, 2010.

[9] M. M. Haklay and P. Weber, "Openstreetmap : User-generated street maps," IEEE Pervasive Computing, vol. 7, no. 4, pp. 12-18, Oct. 2008. [Online]. Available : http://dx.doi.org/10.1109/MPRV.2008.80

[10] Z.-R. Peng, "Urban transportation strategies in chinese cities and their impacts on the urban poor," Transportation Research Board 85th Annual Meeting, p. 14, 2005.

[11] J. Lin, "Bicycles in beijing," project : Transportation (Green Design and the City).

[12] S. Wang, J. Sun, C. Shao, and F. Wang, Evaluation on Vehicle Restriction Measure in Beijing, ch. 39, pp. 433-443. [Online]. Available : http://ascelibrary.org/doi/abs/10.1061/ $41123 \% 28383 \% 2940$

[13] Z. Xin. (2012, November) Subway line 6 to start running in december. China Daily. [Online]. Available : http://www.chinadaily.com.cn/beijing/2012-11/26/content_15998073.htm

[14] P. Hui, A. Chaintreau, J. Scott, R. Gass, J. Crowcroft, and C. Diot, "Pocket switched networks and human mobility in conference environments," in Proceedings of the 2005 ACM SIGCOMM workshop on Delay-tolerant networking, ser. WDTN '05. New York, NY, USA : ACM, 2005, pp. 244-251. [Online]. Available : http://doi.acm.org/10.1145/1080139.1080142 
[15] B. Han, P. Hui, V. Kumar, M. Marathe, J. Shao, and A. Srinivasan, "Mobile data offloading through opportunistic communications and social participation," Mobile Computing, IEEE Transactions on, vol. 11, no. 5, pp. 821-834, May 2012.

[16] E. Mucelli Rezende Oliveira and A. Viana, "Routine-based network deployment for data offloading in metropolitan areas." [Online]. Available : http://hal.inria.fr/hal-00862916 


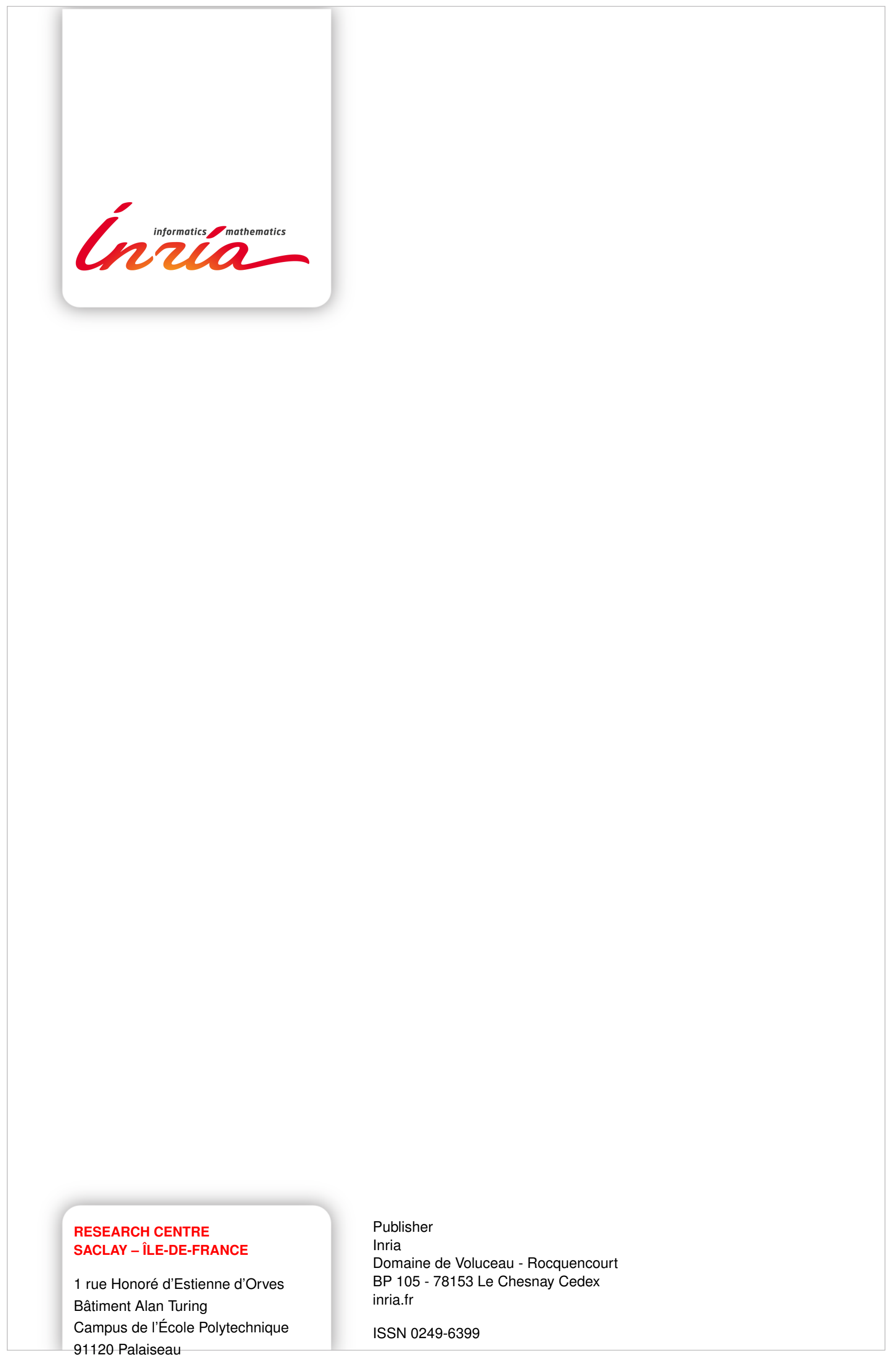

